\title{
Correction to: A Multimedia Adaptive Tutoring System for Mathematics that Addresses Cognition, Metacognition and Affect
}

\author{
Ivon Arroyo $^{1}$ - Beverly Park Woolf ${ }^{2} \cdot$ Winslow Burleson ${ }^{3}$ •

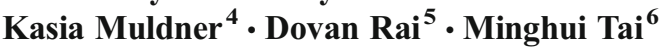

Published online: 22 May 2018

(C) International Artificial Intelligence in Education Society 2018

\section{Correction to: Int J Artif Intell Educ (2014) 24:387-426. https://doi.org/10.1007/s40593-014-0023-y}

The Publisher regrets a spelling error in the family name of the third author. "Winslow Burelson" should be "Winslow Burleson".

The online version of the original article can be found at https://doi.org/10.1007/s40593-014-0023-y

\section{Ivon Arroyo}

iarroyo@wpi.edu

1 Learning Sciences and Technologies, Department of Social Sciences and Policy Studies, Worcester Polytechnic Institute, Worcester, MA, USA

2 School of Computer Science, University of Massachusetts, Amherst, MA, USA

3 New York University College of Nursing, New York University, New York, NY, USA

4 Institute of Cognitive Science, Carleton University, Ottawa, Canada

5 Department of Computer Science, Worcester Polytechnic Institute, Worcester, MA, USA

6 School of Education, University of Massachusetts, Amherst, MA, USA 